\title{
A Pilot Study on Ocular Safety and Efficacy of Infliximab as an Antifibrotic Agent After Experimental Glaucoma Filtration Surgery
}

\author{
Eleni Nikita (D) Alexandre Moulin - Ioannis Vergados - Dimitrios Brouzas • \\ Panagiotis G. Theodossiadis
}

Received: May 17, 2017 / Published online: July 1, 2017

(C) The Author(s) 2017. This article is an open access publication

\section{ABSTRACT}

Introduction: Tumor necrosis factor- $\alpha$ (TNF- $\alpha$ ) is a multifunctional, proinflammatory cytokine that mediates pleiotropic biological functions, especially inflammation and immunoregulation. We hypothesized that blocking TNF- $\alpha$ with a monoclonal antibody would decrease inflammation and subconjunctival scarring in an animal model of experimental filtration surgery.

Methods: In a randomized, prospective, masked-observer study, 30 New Zealand albino rabbits underwent glaucoma filtration surgery. The animals were allocated to receive either intraoperative application of infliximab (group A) or mitomycin C (MMC) at a concentration of

Enhanced content To view enhanced content for this article go to http://www.medengine.com/Redeem/ B798F0600920B5A0.

E. Nikita $(\bowtie) \cdot$ I. Vergados · P. G. Theodossiadis Attikon University Hospital, Athens, Greece e-mail: elenikita@hotmail.co.uk

A. Moulin

Jules Gonin Eye Hospital, Lausanne, Switzerland

D. Brouzas

General Hospital of Athens "G Gennimatas",

Athens, Greece
$0.2 \mathrm{mg} / \mathrm{ml}$ (group B) or balanced salt solution (BSS, control) (group C). Different infliximab doses, namely 1.0, 2.0, 3.0, 4.0, $5.0 \mathrm{mg}$ in $0.1 \mathrm{ml}$, were applied. Bleb survival and characteristics were evaluated over a 30-day period. The animals were killed on postoperative day 15 or 30 . Histology of the operated eyes was performed to evaluate and grade the amount of scarring in each group. Cellular density was evaluated in each case.

Results: Infliximab did not appear to improve outcomes in this model of glaucoma filtration surgery. Bleb survival was significantly higher in the MMC group compared to the other groups ( $p<0.001$ for both comparisons). Vascularity was also significantly lower in the MMC group compared to the other groups $(p=0.018$ for both comparisons). There was a significant decrease in cellular density in the MMC group compared to the control $(p=0.0352)$ and the infliximab group $(p<001)$.

Conclusion: Our results have shown that trabeculectomies in the infliximab group failed faster and displayed more scarring, compared to the control and MMC groups. This outcome suggests that the infliximab doses used in this pilot study resulted in a subconjunctival TNF- $\alpha$ concentration, which acted as a stimulator to fibroblasts.

Keywords: Infliximab; Trabeculectomy; Tumor necrosis factor- $\alpha$ 


\section{INTRODUCTION}

To date, trabeculectomy remains the procedure of choice to lower intraocular pressure and preserve vision for a significant number of patients suffering from glaucoma [1]. However, it induces tissue injury that prompts the body to initiate a precisely orchestrated sequence of events, the process of wound healing $[2,3]$. The latter represents the main determinant of long-term success, as excessive subconjunctival fibrosis, driven by fibroblasts, is the principal cause of surgical failure [4]. Tenon's capsule fibroblasts are activated and guided by a variety of molecules such as interleukins, matrix metalloproteinases, transforming growth factor- $\beta$ (TGF- $\beta$ ), tumor necrosis factor- $\alpha$ (TNF- $\alpha$ ) etc. [5].

The introduction of the antimetabolites 5-fluorouracil (5-FU) and mitomycin C (MMC) has allowed wound-healing modulation, which led to improved outcome of glaucoma filtration surgery [6-8]. However, these agents have been associated with potentially sight-threatening complications [9-15]. Therefore, the use of alternative antifibrotic agents with more specific actions and less cytotoxicity became evident. Over the last couple of years new antiscarring agents have been evaluated, such as matrix metalloproteinase inhibitors, alkylphosphocholines, anti-TGF- $\beta 2$ antibody, Rho-associated protein kinase inhibitors, and anti-vascular endothelial growth factors [16-20].

TNF- $\alpha$ is a multifunctional cytokine that regulates inflammation, host defense, immune responses, apoptosis, and organ development. It is mainly produced by macrophages, but may also be released by $\mathrm{T}$ and $\mathrm{B}$ lymphocytes, fibroblasts, endothelial and epithelial cells [21].

Evidence in the literature from animal and human studies suggests that TNF- $\alpha$ is an important mediator in intraocular inflammation and angiogenesis as well. In an animal model of diabetic retinopathy, the administration of TNF- $\alpha$ inhibitors was found to reduce leukocyte adhesion and inhibit blood-retinal barrier breakdown [22]. In experimental autoimmune uveoretinitis, systemic treatment with anti-TNF- $\alpha$ serum significantly ameliorated disease by decreasing antigen priming during the afferent stage of inflammation [23].
There is also considerable evidence that TNF- $\alpha$ plays a key role in scarring. Antibody blockage of TNF- $\alpha$, administered either during the acute inflammatory or scarring phase of nephrotoxic nephritis in experimental crescentic glomerulonephritis, showed that inhibition of TNF- $\alpha$ reduces inflammation and renal fibrosis [24]. Neutralization of endogenous TNF- $\alpha$ in rats with crescentic nephritis prevented acute glomerular inflammation and crescent formation [25]. Anti-TNF- $\alpha$ treatment of patients with Crohn's colitis was proven to decrease the levels of serum basic fibroblast growth factor and vascular endothelial growth factor, two cytokines known to promote repair in human inflammation by modulating fibroblast and subsequently downregulate the process of intestinal fibrogenesis [26].

Infliximab (Remicade; Roche, Manheim, Germany) is a chimeric IgG1 monoclonal antibody specific for human TNF- $\alpha$ and is currently approved for the treatment of various automimmune conditions [27-30].

Regarding ocular diseases, its efficacy has been evaluated for the treatment of uveitis [31-33] and keratitis [34]. Few case reports have demonstrated that in patients on systemic infliximab for uveitis secondary to Behçet disease, neither ocular inflammatory attacks nor infectious complications were encountered post glaucoma filtration surgery $[35,36]$.

To our knowledge, the safety and efficacy of infliximab as a topical antifibrotic agent after glaucoma filtration surgery has never been reported. In this study we describe the use of intraoperative infliximab injections in a rabbit model of glaucoma filtration surgery. The study was designed to determine whether intraoperative infliximab can be safe and whether it can improve bleb survival, compared to a control group and a group receiving intraoperative MMC (current gold standard).

\section{METHODS}

\section{Animals}

Thirty New Zealand albino rabbits, each weighing $2-3 \mathrm{~kg}$, between 12 and 14 weeks old 
were selected for this study. The study protocol was reviewed and approved by the ethics committee of the Greek University of Athens. All animals were treated in accordance with the ARVO Statement for the Use of Animals in Ophthalmic and Vision Research.

Slit lamp examination was performed on all eyes before the study. Animals with corneal or conjunctival damage before the study were excluded.

\section{Surgical Procedure}

Infliximab (Remicade; Roche) was reconstituted with sterile saline solution. Five different infliximab doses were tested, namely 1.0, 2.0, $3.0,4.0,5.0 \mathrm{mg}$ in $0.1 \mathrm{ml}$, were applied. Glaucoma filtration surgery was performed on the right eye of each rabbit by a single surgeon with experience in glaucoma filtration surgery. General anesthesia was induced by administration of ketamine hydrochloride $50 \mathrm{mg} / \mathrm{kg}$ and xylazine hydrochloride $5 \mathrm{mg} / \mathrm{kg}$. Partial thickness 7-0 silk suture was passed through the superior peripheral cornea and the eye was infraducted. A fornix-based conjunctival flap was fashioned in the superior quadrant with blunt dissection of the subconjunctival space to a distance of $15 \mathrm{~mm}$ behind the limbus, and the sclera was exposed. A rectangular, partial thickness $(3 \times 4 \mathrm{~mm})$ scleral flap was then prepared with a crescent knife, until the blade was just visible in the anterior corneal stroma. At that point each operated eye was randomly allocated to receive intraoperative application of either infliximab of different concentrations (group A), or MMC (Kyowa Hakko Kogyo Co Ltd) at a concentration of $0.2 \mathrm{mg} / \mathrm{ml}$ (group B) or physiological saline (Balanced Salt Solution; Alcon Laboratories) (group C). Five sponges measuring $3 \times 1 \mathrm{~mm}$ were cut and soaked in one of the three agents and subsequently placed between the conjunctiva and the sclera, over the determined filtration area. After $3 \mathrm{~min}$ sponges were removed and the area was irrigated with $15 \mathrm{ml}$ of physiological saline. Then a $500-\mu \mathrm{m}$ sclerostomy with peripheral iridectomy was performed. The scleral flap was loosely sutured with two 10-0 nylon sutures.
The conjunctiva was closed with one single running 8-0 Vicryl suture. Intracameral cefuroxime $1 \mathrm{mg} / 0.1 \mathrm{ml}$ and subconjunctival dexamethasone $3.3 \mathrm{mg} / \mathrm{ml}$ were administered at the end of the procedure. Dexamethasone and tobramycin eye drops (Tobradex; Tobradex, Alcon) were used topically after the surgical procedure four times daily for a week.

\section{Clinical Assessment}

Slit lamp examination was used to evaluate the anterior chamber depth and inflammation, changes in cornea, conjunctival appearance, and drainage area. Assessment of both eyes (contralateral untreated eye used as control) was made on the first postoperative day and thereafter once weekly, until death, with a technique previously described by Mead et al. [18]. Bleb characteristics were assessed. The drainage bleb vascularity characteristics were graded regarding the conjunctival area surrounding the bleb and scoring the appearance $(0$, avascular; +1 , normal vascularity; +2 , hyperemic; and +3 , very hyperemic). Slit lamp examination was performed to identify both anterior chamber activity ( 0 , quiet; 1 , cells; 2 , fibrin; and 3 , hypopyon) and anterior chamber depth, which was recorded as deep $(+2)$, shallow $(+1)$, or flat (0). Assessment of corneal epitheliopathy was made after topical instillation of lignocaine fluorescein into the right eye and was graded according to the area of the cornea affected $(0$, nil; $1,<25 \% ; 2,<50 \% ; 3,<75 \% ; 4,<100 \% ; 5$, $100 \%)$.

As a result of the limited provision of non-contact tonometers, IOP measurements were not included in the study. However, the rabbit model of filtration surgery represents a model of subconjunctival scarring and not of glaucoma and therefore significant IOP differences between groups were unlikely to be detected [18].

\section{Histology Analysis}

On days 15 or 30 , animals were killed with a lethal intravenous injection of phenobarbital 
$(120 \mathrm{mg} / \mathrm{kg})$, and the tissues were processed for histology. The surgical eye was enucleated. The upper lid was left intact, attached to the globe, to preserve the architecture of the superior fornix and conjunctival tissues around the drainage site. All the eyes were fixed in 4\% formaldehyde and embedded in paraffin wax. Sequential $5-\mu \mathrm{m}$ sections of the operative wound site were prepared. The following histological staining was performed: hematoxylin and eosin (for total cellularity, inflammation), Masson trichrome (for scar formation, collagen density, and orientation), and oxidation aldehyde fuchsin (elastic fibers). Cellular density in the bleb was regarded as a good parameter to evaluate the bleb's function as it depends upon inflammation, fibrosis, and edema of the bleb. The mean cellular density was evaluated in each case in five high power fields $\left(\times 400,0.18 \mathrm{~mm}^{2}\right)$. The fibrosis and inflammation were graded as absent, mild $(<10 \%)$, moderate $(<40 \%)$, and severe $(>40 \%)$.

\section{Statistical Analysis}

Statistical analysis was performed to determine the differences between the three treatment groups. Qualitative variables were expressed as absolute and relative frequencies. For the comparison of proportions Fisher's exact tests were used. Random effects logistic regression analyses with dependent variables bleb thickness, vascularity, and height were used to evaluate their changes among the different groups over the follow-up. Odds ratio (OR) with standard errors (SE) were computed from the results of these models. To investigate if changes during follow-up were different between the study groups, the interaction term of time and group was tested in the models. Kaplan-Meier survival estimates for bleb failure were graphed over the follow-up period, for each study group. Logrank tests were used to compare survival curves between the three groups. All reported $p$ values are two-tailed. Statistical significance was set at $p<0.05$ and analyses were conducted using STATA statistical software (version 11.0).

\section{RESULTS}

\section{Histopathology Features}

\section{Bleb Analysis}

In all groups there was variability in bleb characteristics, including well-formed ones, edematous without significant inflammation, to very small blebs with significant fibrosis. The MMC group had more edematous and formed blebs compared to the other groups. The infliximab group had overall smaller blebs with significant fibrosis. The inflammation was overall mild and limited to some lymphocytes and occasional plasmocytes more frequently located at the limbus or the superficial stroma. In some cases a limited foreign-body-type reaction could be identified around suture material (Fig. 1).

\section{Statistical Analysis}

The mean cellular density in the bleb of the infliximab group at 15 days was 50.7 cells/HPF $(\times 400) \pm 4.9 \quad(\mathrm{SEM})$ and 36.2 cells $/ \mathrm{HPF} \pm 7$ (SEM) in the MMC group. The mean cellular density in the control group at 15 days was 52.6 cells/HPF $(\times 400) \pm 3.6(\mathrm{SEM})$. The mean cellular density in the bleb of the infliximab group at 30 days was 51.3 cells/HPF $(\times 400) \pm 5.8(\mathrm{SEM})$ and 42.25 cells $/ \mathrm{HPF} \pm 3.6$ (SEM) in the MMC group. There was a significant decrease in cellular density in the MMC group compared to the control group $(p=0.0186$; Student's $t$ test $)$ and the infliximab group $(p<0.01)$. There was no significant decrease in cellular density in the infliximab group compared to the control group. There were no statistical significant differences in cellular density between the blebs treated with various concentrations of infliximab.

\section{Clinical Features}

In keeping with previous studies [19], anterior chamber (AC) depth was shallow on the first postoperative day and was deep in all rabbits by day 7. AC remained deep in all eyes, regardless of the treatment group throughout the study. 

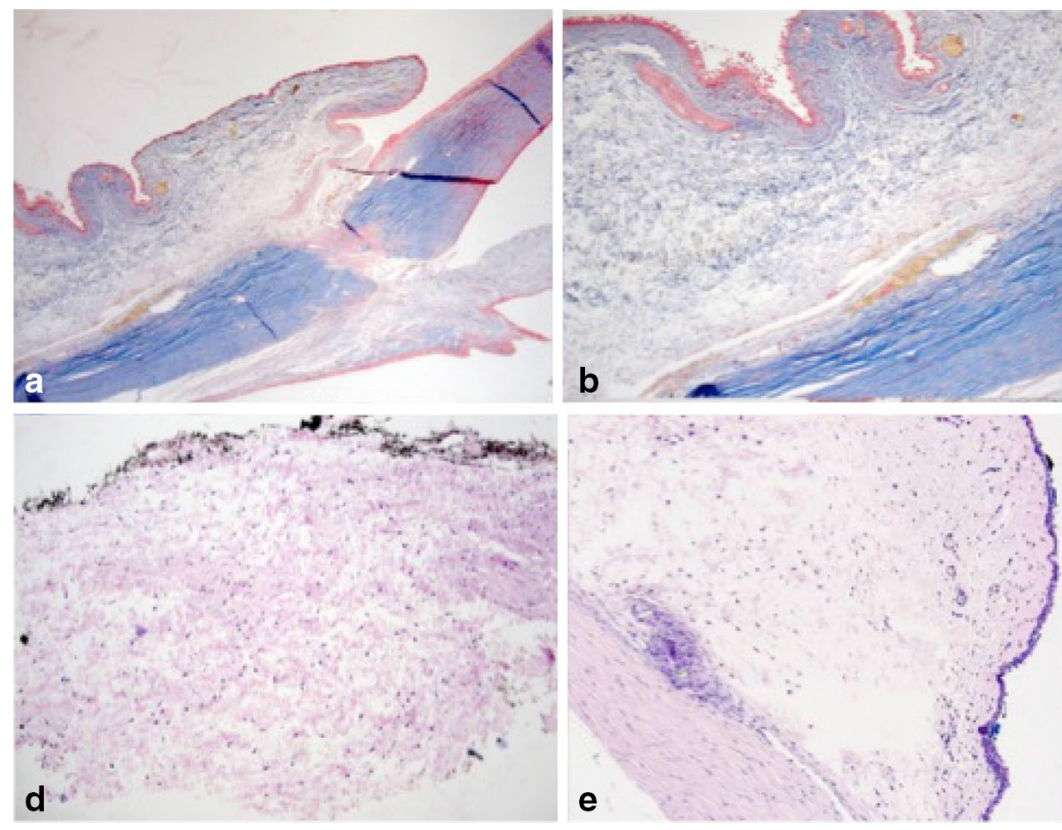

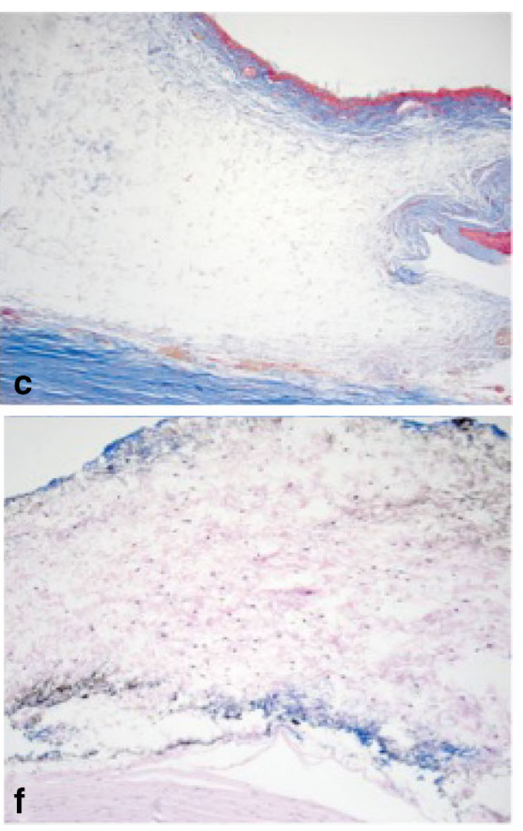

Fig. 1 Histologic characteristics of postoperative blebs at day 15 . The images show representative sections from eyes in each group. a, b Masson trichrome stain of the bleb of an eye in the control group. a [Original magnification $\times 24$; b original magnification $\times 63$, cellular density 43 cells/HPF $\left.\left(\times 400,0.18 \mathrm{~mm}^{2}\right)\right]$. c Masson trichrome stain of the bleb of an eye in the MMC group (original magnification $\times 63$, cellular density 23 cells/HPF).

During the course of the study, local tissue reaction to treatment was assessed by bleb and conjunctival vascularity as well as bleb thickness.

No cases of epithelial defects or endophthalmitis were recorded in either treatment group.

Failure of surgery was defined by the appearance of a flat, vascularized or scarred bleb associated with a deep anterior chamber. At day $28,8(80 \%)$ of the control group and $10(100 \%)$ of the infliximab group had failed compared to $1(11.1 \%)$ in the MMC group. The bleb failed at a mean of 9.8 days $(\mathrm{SE}=1.1)$ with infiximab, 26.4 days $(\mathrm{SE}=1.5)$ with $\mathrm{MMC}$, and 16.8 days $(\mathrm{SE}=1.9)$ for the controls (Table 1). A significant difference in bleb survival was observed between groups (log rank; $p<0.001$ ) (Fig. 2). More specifically, greater survival was found in the MMC group compared to the infliximab and control groups $(p<0.001$ for both d Hemotoxylin-eosin stain of the bleb of an eye in the control group (original magnification $\times 63$, cellular density 39 cells/HPF). e, f Hemotoxylin-eosin stain of the bleb of an eye in the 4-mg infliximab group (e anterior part of the bleb; $\mathbf{f}$ posterior part of the bleb; original magnification $\times 63$, cellular density 49 cells/HPF)

Table 1 Time at which the blebs failed after surgery in each treatment group

\begin{tabular}{llllll}
\hline Group & \multicolumn{5}{l}{ Days after surgery } \\
\cline { 2 - 6 } & $\mathbf{1}$ & $\mathbf{7}$ & $\mathbf{1 4}$ & $\mathbf{2 1}$ & $\mathbf{2 8}$ \\
\hline Control & 0 & 0 & 8 & 0 & 2 \\
Infliximab & 0 & 6 & 4 & 0 & 0 \\
MMC & 0 & 0 & 1 & 0 & 0 \\
\hline
\end{tabular}

The mean day of failure was 9.8 for infliximab, 26.4 for MMC, and 16.8 for the controls, $n=10$ in all groups

comparisons), while lower survival was found in the infliximab group compared to controls $(p=0.003)$. During the follow-up, all cases failed in the control and infliximab groups, while only one case failed in the MMC group.

Postoperative measurements of bleb thickness, for each group, are presented in Table 2 . 


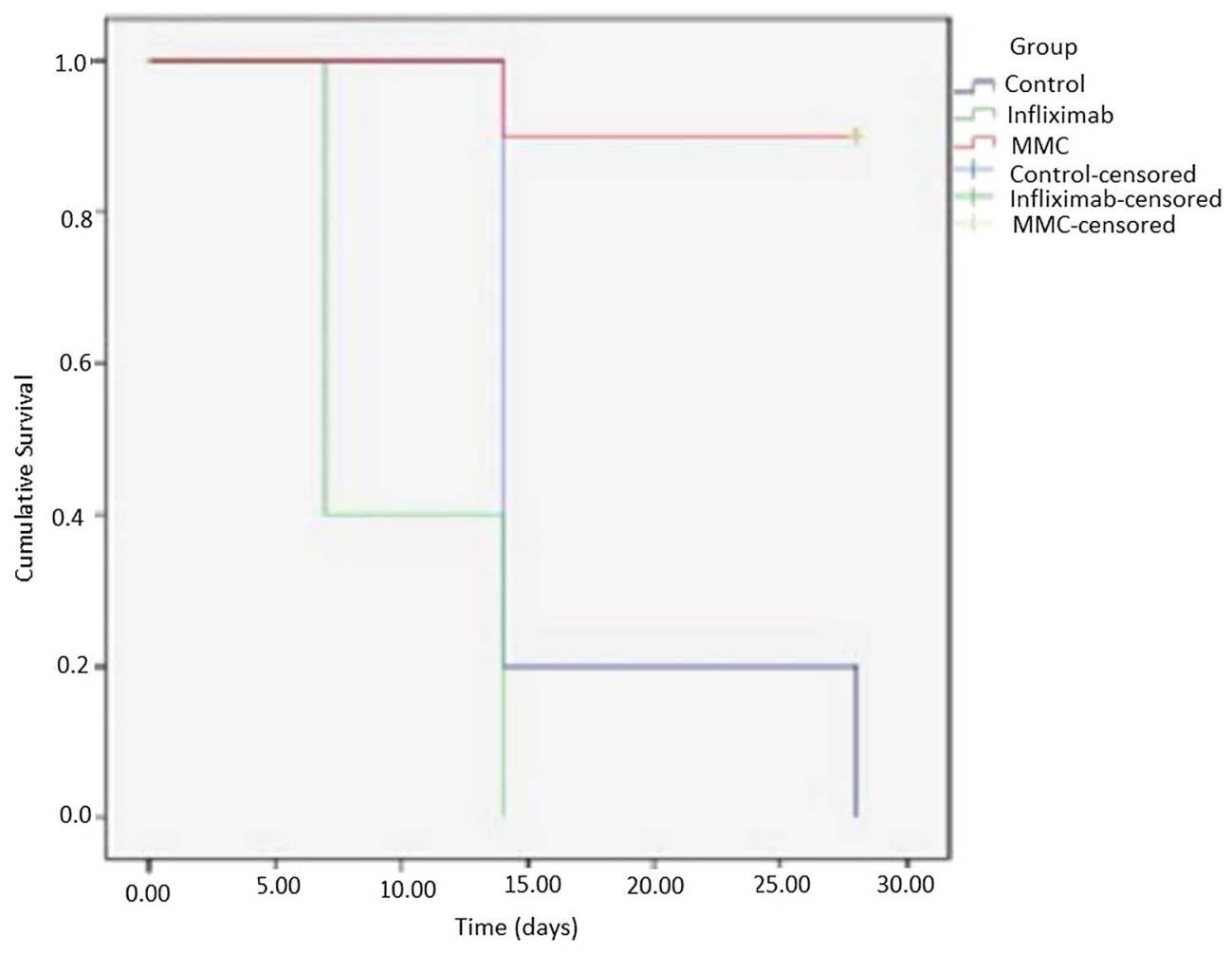

Fig. 2 Kaplan-Meier estimates showing bleb survival curves for the study groups

There were no significant differences between the study groups at each time point $(p>0.050)$.

Postoperative measurements of bleb vascularity for each group are presented in Table 3. At the first and seventh postoperative day, the percentage of moderate/severe vascularity was significantly higher in the control group compared to the MMC group. Also, the percentages of moderate/severe vascularity decreased significantly during follow-up measurements in the infliximab group $(\beta=-0.02 ; \mathrm{SE}=0.01 ; p=0.014)$ and in the control group $(\beta=-0.04 ; \mathrm{SE}=0.01 ; p<0.001)$, while in the MMC group there was no significant change $(\beta=0.002 ; \mathrm{SE}=0.01 ; p=0.662)$ as indicated from the interaction term of the model (Fig. 3).

Postoperative measurements of bleb height, for each group, are presented in Table 4. All rabbits had a bleb height of 1 or 2 at the first postoperative day, regardless of the group. At day 7 and day 21 postsurgery, the percentages of bleb height 1 or 2 were significantly higher in the MMC group compared to infliximab group. Moreover, at day 14 and day 28 the percentages of bleb height 1 or 2 were significantly higher in the MMC group compared to both the infliximab and control groups.

Random effects logistic regression analyses, for bleb thickness, showed a significant increase in the likelihood for having thick bleb during the follow-up $\left(\mathrm{OR}_{\text {time }}=1.09,96 \%\right.$ CI 1.02-1.17, $p=0.014)$. Also, a significant interaction effect of time with group was found ( $p=0.031$; Fig. 4 ) indicating that in the infliximab and MMC groups there was an increase in the probability of having thick bleb, whilst no changes were observed in the control group.

Random effects analyses for vascularity showed a significant decrease in the odds of having moderate or severe vascularity during follow-up $\left(\mathrm{OR}_{\text {time }}=0.86,96 \%\right.$ CI $0.65-0.89$, $p=0.001)$. Lower odds for the presence of moderate or severe vascularity were found in the infliximab group as compared to controls $(\mathrm{OR}=0.06,96 \%$ CI $0.01-0.49, p=0.009)$ and in the MMC group as compared to controls $(\mathrm{OR}=0.01,96 \%$ CI 0.001-0.13, $p=0.002)$. 
Table 2 Postoperative measurements of bleb thickness for each group

\begin{tabular}{|c|c|c|c|c|c|c|c|c|c|c|}
\hline \multirow[b]{3}{*}{ Group } & \multicolumn{10}{|c|}{ Thickness } \\
\hline & \multicolumn{2}{|l|}{ Day 1} & \multicolumn{2}{|l|}{ Day 7} & \multicolumn{2}{|l|}{ Day 14} & \multicolumn{2}{|l|}{ Day 21} & \multicolumn{2}{|l|}{ Day 28} \\
\hline & $\begin{array}{l}\text { Thin } \\
N(\%)\end{array}$ & $\begin{array}{l}\text { Thick } \\
N(\%)\end{array}$ & $\begin{array}{l}\text { Thin } \\
N(\%)\end{array}$ & $\begin{array}{l}\text { Thick } \\
N(\%)\end{array}$ & $\begin{array}{l}\text { Thin } \\
N(\%)\end{array}$ & $\begin{array}{l}\text { Thick } \\
N(\%)\end{array}$ & $\begin{array}{l}\text { Thin } \\
N(\%)\end{array}$ & $\begin{array}{l}\text { Thick } \\
N(\%)\end{array}$ & $\begin{array}{l}\text { Thin } \\
N(\%)\end{array}$ & $\begin{array}{l}\text { Thick } \\
N(\%)\end{array}$ \\
\hline Control & $7(70.0)$ & $3(30.0)$ & $\begin{array}{l}10 \\
\quad(100.0)\end{array}$ & $0(0.0)$ & $9(90.0)$ & $1(10.0)$ & $5(100.0)$ & $0(0.0)$ & $4(80.0)$ & $1(20.0)$ \\
\hline Infliximab & $\begin{array}{l}10 \\
\quad(100.0)\end{array}$ & $0(0.0)$ & $7(70.0)$ & $3(30.0)$ & $6(60.0)$ & $4(40.0)$ & $3(60.0)$ & $2(40.0)$ & $2(40.0)$ & $3(60.0)$ \\
\hline MMC & $9(100.0)$ & $0(0.0)$ & $8(88.9)$ & $1(11.1)$ & $7(77.8)$ & $2(22.2)$ & $2(50.0)$ & $2(50.0)$ & $2(50.0)$ & $2(50.0)$ \\
\hline $\begin{array}{c}p^{*} \text { control vs } \\
\text { infliximab }\end{array}$ & 0.211 & & 0.211 & & 0.303 & & 0.444 & & 0.524 & \\
\hline $\begin{array}{c}p^{*} \text { control vs } \\
\text { MMC }\end{array}$ & 0.211 & & 0.474 & & 0.582 & & 0.167 & & 0.524 & \\
\hline $\begin{array}{c}p^{*} \text { infliximab } \\
\text { vs MMC }\end{array}$ & $-^{+}$ & & 0.582 & & 0.628 & & 1.000 & & 1.000 & \\
\hline
\end{tabular}

The interaction term of time with group as presented in Fig. 3 was significant $(p=0.018)$ showing that in the MMC group the likelihood for the presence of moderate or severe vascularity was lower and constant, while in the two others groups a decrease was recorded.

With regards to bleb height analysis, a significant decrease in the likelihood for the presence of heights $1-2 \quad\left(\mathrm{OR}_{\text {time }}=0.32,96 \% \mathrm{CI}\right.$ 0.11-0.97, $p=0.045)$ was shown. The MMC group had greater odds for the presence of heights $1-2$, while the no interaction effect was found indicating that the three groups had similar changes during the follow-up (Fig. 5).

\section{DISCUSSION}

Glaucoma filtration surgery induces tissue injury that stimulates the body to commence the process of wound healing [37]. TNF- $\alpha$ plays a vital role throughout this process, as it participates in clotting, inflammation, and apoptosis [21, 38]. We hypothesized that blocking TNF- $\alpha$ with infliximab would reduce both inflammation and fibrosis post glaucoma filtration surgery and consequently enhance bleb survival.

Multiple studies in animal models and humans have demonstrated the beneficial effect of TNF- $\alpha$ blockage in the treatment of systemic and ophthalmic inflammatory diseases $[22,23,27-30]$. However, the in vivo and in vitro data on the role of infliximab in angiogenesis and wound healing have been controversial.

Angiogenesis is indispensable in the formation of granulation tissue during the proliferative phase of wound healing. TNF- $\alpha$ can trigger opposite signaling pathways involved in angiogenesis, evoking apoptosis or cell survival and proliferation, depending on the tissues and underlying pathology [39-41]. Regatieri et al. examined the effects of infliximab in angiogenesis modulation and glycosaminoglycan expression in choroidal neovascularization lesions and concluded that it demonstrates a dual effect depending on the concentration and it may reduce angiogenesis and glycosaminoglycan expression at low doses, whereas opposite effects are observed at high doses [42]. 


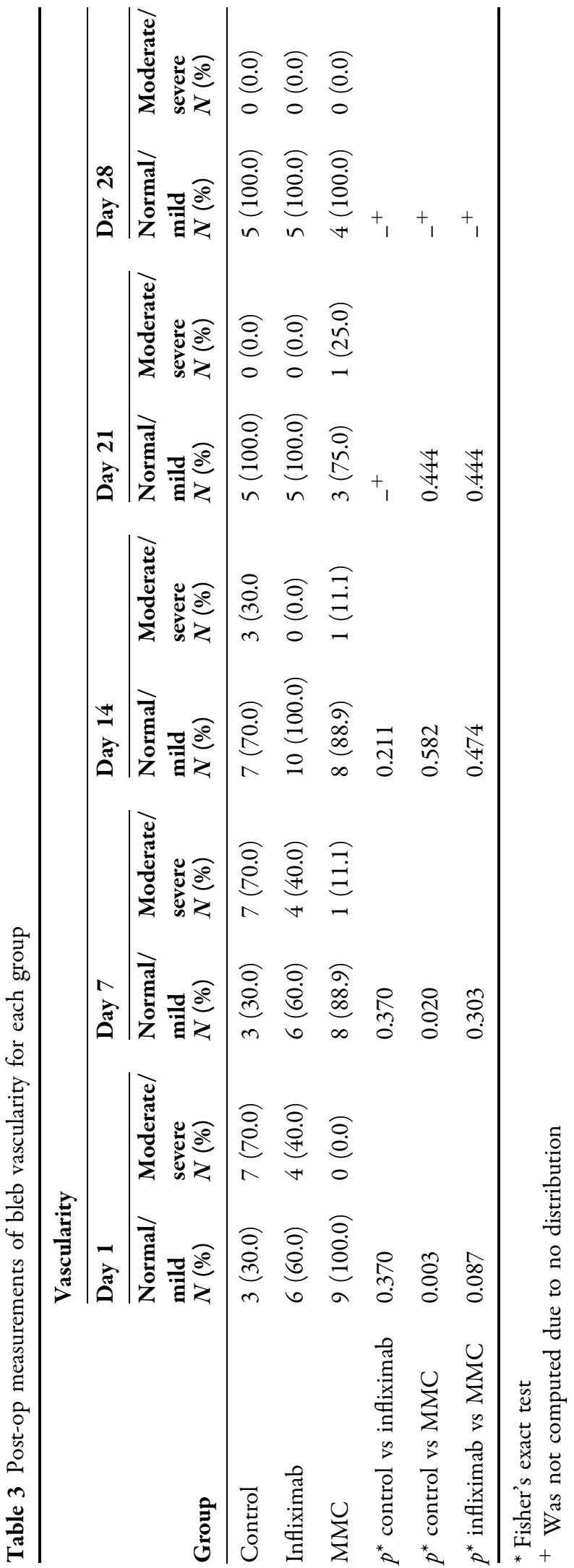

With regards to wound healing and fibrosis, the results of studies are equally equivocal $[43,44]$. Multiple studies assessing the systemic effect of anti-TNF in renal and colorectal fibrosis reported a favorable result of the antibody on tubulointerstitial scarring and interstitial fibrogenesis [24-26]. Mooney et al. reported that local application of TNF- $\alpha$ accelerated wound healing in murines [45]. In contrast Rapala et al. [43] and Salomon et al. [44] concluded that TNF- $\alpha$ impaired wound healing. These opposing effects of TNF- $\alpha$ could be attributed to its effect on the production of collagen and collagenase. Austgulen et al. suggested that TNF- $\alpha$ affects the accumulation of extracellular matrix molecules by promoting or inhibiting the activity of collagenases [46]. Other studies though indicate that TNF- $\alpha$ may play a predominantly catabolic role in situ by inhibiting fibronectin production, indirectly increasing dermal fibroblast elaboration of collagenase and proteoglycan activities, thus causing the degradation of collagen and glycosaminoglycan [47].

The opposing actions of TNF- $\alpha$ could be explained as follows. TNF is a pluripotent, proinflammatory cytokine that mediates pleiotropic biological functions as a direct consequence of its ability to induce the expression of a large number of gene products. With regards to its inflammatory properties, binding to TNFR2 may either induce activation of the NF- $\kappa \mathrm{B}$ pathway with subsequent expression of several anti-apoptotic genes or conversely stimulate apoptosis by inhibiting the NF- $\kappa B$ pathway. The model proposed to explain the contradictory functions of TNF suggests that apoptosis is induced when the complex of TNF- $\alpha$ /TNFR1 is internalized within endocytic vesicles with subsequent altered signaling pathways. However it is unclear which factors define the cascade of events post formation of the TNF- $\alpha /$ TNFR1 complex [21]. TNF- $\alpha$ concentration my play a role. Reports have demonstrated that at low concentrations TNF- $\alpha$ may act on fibroblasts as a growth inducer, by stimulating proliferation. In contrast, at higher concentrations, it can act as a growth inhibitor, by blocking growth triggered by serum and other cytokines [48]. 


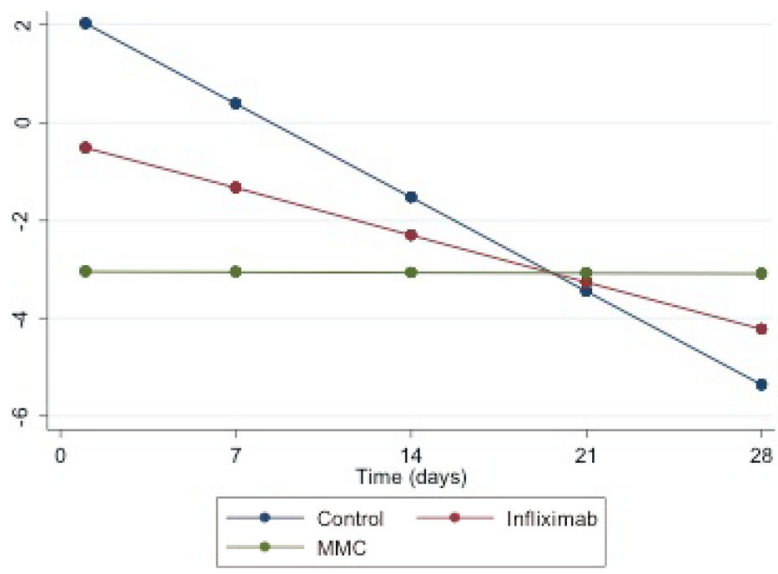

Fig. 3 Linear predictors for moderate/severe bleb vascularity through follow-up period, for each study group

Our results have shown that trabeculectomies in the infliximab group failed faster and displayed more scarring, compared to the control and MMC groups. Vascularity though was less significant in the infliximab group compared to the control group. This outcome suggests that the infliximab doses used in this pilot study resulted in a subconjunctival TNF- $\alpha$ concentration, which probably acted as a stimulator to fibroblasts, but not for angiogenesis.

In order to reproduce the current golden standard technique of MMC application, infliximab was administered under the conjunctiva through soaked sponges, in a predetermined filtration area, and then irrigated with saline. It is unknown whether the same concentrations of infliximab would have produced different clinical outcomes had it not been washed out or had it been administered through a subconjunctival injection at the beginning of surgery.

Our data also showed a statistically significant decrease in cellular density in the MMC group, compared to the other groups. This echoes multiple studies demonstrating that MMC causes widespread cell death and apoptosis [12].

No differences were found in cellular density and scarring amongst various concentrations of infliximab. This could imply that for topical infliximab administration, larger concentration variances would be required to produce a detectable clinical difference.

Table 4 Post-op measurements of bleb height for each group

\begin{tabular}{|c|c|c|c|c|c|c|c|c|c|c|}
\hline \multirow[b]{3}{*}{ Group } & \multicolumn{10}{|l|}{ Height } \\
\hline & \multicolumn{2}{|l|}{ Day 1} & \multicolumn{2}{|l|}{ Day 7} & \multicolumn{2}{|l|}{ Day 14} & \multicolumn{2}{|l|}{ Day 21} & \multicolumn{2}{|l|}{ Day 28} \\
\hline & $\begin{array}{l}\mathbf{0} \\
N(\%)\end{array}$ & $\begin{array}{l}1-2 \\
N(\%)\end{array}$ & $\begin{array}{l}\mathbf{0} \\
N(\%)\end{array}$ & $\begin{array}{l}1-2 \\
N(\%)\end{array}$ & $\begin{array}{l}0 \\
N(\%)\end{array}$ & $\begin{array}{l}1-2 \\
N(\%)\end{array}$ & $\begin{array}{l}\mathbf{0} \\
N(\%)\end{array}$ & $\begin{array}{l}1-2 \\
N(\%)\end{array}$ & $\begin{array}{l}\mathbf{0} \\
N(\%)\end{array}$ & $\begin{array}{l}1-2 \\
N(\%)\end{array}$ \\
\hline Control & $0(0)$ & $10(100.0)$ & $2(20.0)$ & $8(80.0)$ & $7(70.0)$ & $3(30.0)$ & $3(60.0)$ & $2(40.0)$ & $5(100.0)$ & $0(0)$ \\
\hline Infliximab & $0(0)$ & $10(100.0)$ & $6(60.0)$ & $4(40.0)$ & $10(100.0)$ & $0(0.0)$ & $5(100.0)$ & $0(0)$ & $5(100.0)$ & $0(0)$ \\
\hline MMC & $0(0)$ & $9(100.0)$ & $0(0.0)$ & $9(100.0)$ & $1(11.1)$ & $8(88.9)$ & $1(25.0)$ & $3(75.0)$ & $1(25.0)$ & $3(75.0)$ \\
\hline $\begin{array}{c}p^{*} \text { control vs } \\
\text { infliximab }\end{array}$ & $-^{+}$ & & 0.170 & & 0.211 & & 0.444 & & $-^{+}$ & \\
\hline $\begin{array}{c}p^{*} \text { control vs } \\
\mathrm{MMC}\end{array}$ & $-^{+}$ & & 0.474 & & 0.020 & & 0.524 & & 0.048 & \\
\hline $\begin{array}{c}p^{*} \text { infliximab } \\
\text { vs MMC }\end{array}$ & $-^{+}$ & & 0.011 & & $<0.001$ & & 0.048 & & 0.048 & \\
\hline
\end{tabular}

${ }^{*}$ Fisher's exact test

+ Was not computed due to no distribution 


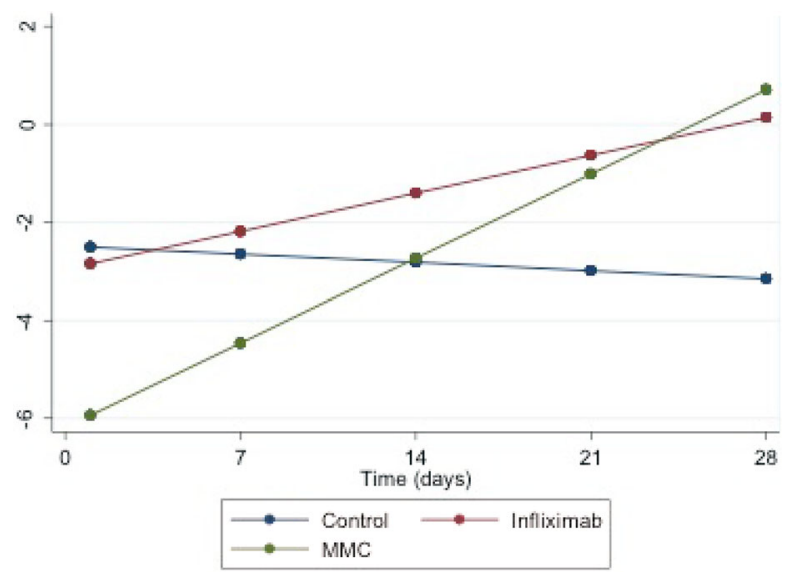

Fig. 4 Linear predictors for thick bleb through follow-up period, for each study group

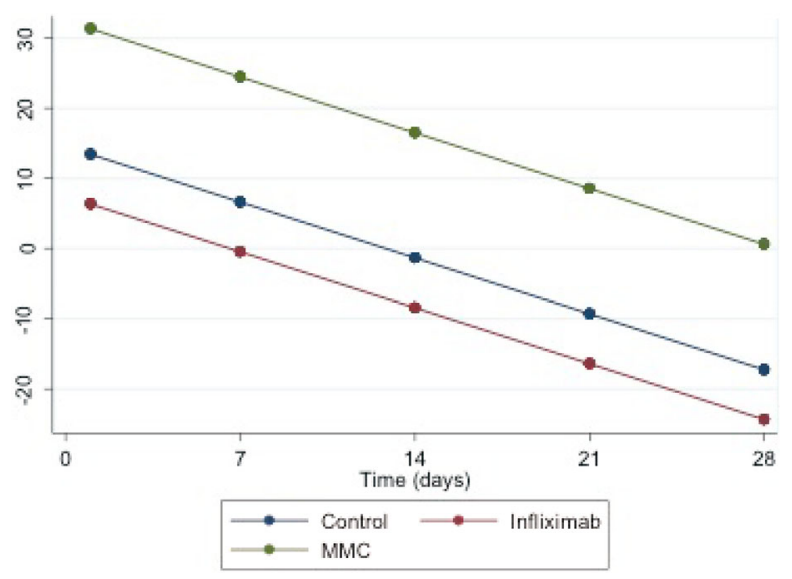

Fig. 5 Linear predictors for bleb height through follow-up period, for each study group

Our study is preliminary and is limited by the following considerations. The number of rabbits used in this study was not sufficient to draw final conclusions regarding intraoperative safety and efficacy of infliximab. Cell culture experiments, which would demonstrate the optimum infliximab concentration with no cellular toxicity, while demonstrating maximum inhibition of angiogenesis and fibrosis, were not performed. Also, as a result of limitations in human resources, a 7-day interval time in-between observations under anesthesia was chosen, resulting in possible overestimation of the exact timing of bleb failure. These are important caveats when extrapolating our studies to safety and efficacy in human subjects.
Further studies will be required to determine the effective dose of intraoperative infliximab.

\section{CONCLUSION}

Our outcomes indicate that infliximab, when administered subconjunctivally during experimental glaucoma filtration surgery in concentrations ranging from 10 to $50 \mathrm{mg} / \mathrm{ml}$, accelerates scarring and bleb failure. The ideal antifibrotic agent, which will modulate wound healing whilst minimizing side effects, is yet to be defined.

\section{ACKNOWLEDGEMENTS}

No funding or sponsorship was received for this study or publication of this article. The article processing charges were funded by the authors. All authors had full access to all of the data in this study and take complete responsibility for the integrity of the data and accuracy of the data analysis.

All named authors meet the International Committee of Medical Journal Editors (ICMJE) criteria for authorship for this manuscript, take responsibility for the integrity of the work as a whole, and have given final approval for the version to be published.

Disclosures. Eleni Nikita, Alexandre Moulin, Ioannis Vergados, Dimitrios Brouzas, and Panagiotis G. Theodossiadis have nothing to disclose.

Compliance with Ethics Guidelines. All institutional and national guidelines for the care and use of laboratory animals were followed.

Open Access. This article is distributed under the terms of the Creative Commons Attribution-NonCommercial 4.0 International License (http://creativecommons.org/licenses/ by-nc/4.0/), which permits any noncommercial use, distribution, and reproduction in any medium, provided you give appropriate credit to the original author(s) and the source, provide 
a link to the Creative Commons license, and indicate if changes were made.

\section{REFERENCES}

1. Ramulu PY, Corcoran KJ, Corcoran SL, Robin AL. Utilization of various glaucoma surgeries and procedures in Medicare beneficiaries from 1995 to 2004. Ophthalmology. 2007;114(12):2265-70.

2. Skuta GL, Parrish RK 2nd. Wound healing in glaucoma filtering surgery. Surv Ophthalmol. 1987;32(3):149-70.

3. Addicks EM, Quigley HA, Green WR, Robin AL. Histologic characteristics of filtering blebs in glaucomatous eyes. Arch Ophthalmol. 1983;101(5):795-8.

4. Fuller JR, Bevin TH, Molteno AC, Vote BJ, Herbison P. Anti-inflammatory fibrosis suppression in threatened trabeculectomy bleb failure produces good long term control of intraocular pressure without risk of sight threatening complications. $\mathrm{Br} \mathrm{J}$ Ophthalmol. 2002;86(12):1352-4.

5. Daniels JT, Occleston NL, Crowston JG, et al. Understanding and controlling the scarring response: the contribution of histology and microscopy. Microsc Res Tech. 1998;42(5):317-33.

6. Van Buskirk EM. Five-year follow-up of the Fluorouracil Filtering Surgery Study. Am J Ophthalmol. 1996;122(5):751-2.

7. Kitazawa $\mathrm{Y}$, Kawase $\mathrm{K}$, Matsushita $\mathrm{H}$, Minobe M. Trabeculectomy with mitomycin. A comparative study with fluorouracil. Arch Ophthalmol. 1991;109(12):1693-8.

8. Katz GJ, Higginbotham EJ, Lichter PR, et al. Mitomycin $C$ versus 5 -fluorouracil in high-risk glaucoma filtering surgery. Extended follow-up. Ophthalmology. 1995;102(9):1263-9.

9. Beckers HJ, Kinders KC, Webers CA. Five-year results of trabeculectomy with mitomycin C. Graefe's archive for clinical and experimental ophthalmology=Albrecht von Graefes Archiv fur klinische und experimentelle. Graefes Arch Clin Exp Ophthalmol. 2003;241(2):106-10.

10. WuDunn D, Cantor LB, Palanca-Capistrano AM, et al. A prospective randomized trial comparing intraoperative 5-fluorouracil vs mitomycin $\mathrm{C}$ in primary trabeculectomy. Am J Ophthalmol. 2002;134(4):521-8.
11. Jampel HD, Pasquale LR, Dibernardo C. Hypotony maculopathy following trabeculectomy with mitomycin C. Arch Ophthalmol. 1992;110(8):1049-50.

12. Khaw PT, Doyle JW, Sherwood MB, Grierson I, Schultz G, McGorray S. Prolonged localized tissue effects from 5-minute exposures to fluorouracil and mitomycin C. Arch Ophthalmol. 1993;111(2):263-7.

13. Lamping KA, Belkin JK. 5-Fluorouracil and mitomycin C in pseudophakic patients. Ophthalmology. 1995;102(1):70-5.

14. Parrish R, Minckler D. "Late endophthalmitis"filtering surgery time bomb? Ophthalmology. 1996;103(8):1167-8.

15. Stamper RL, McMenemy MG, Lieberman MF. Hypotonous maculopathy after trabeculectomy with subconjunctival 5-fluorouracil. Am J Ophthalmol. 1992;114(5):544-53.

16. Wong TT, Mead AL, Khaw PT. Matrix metalloproteinase inhibition modulates postoperative scarring after experimental glaucoma filtration surgery. Invest Ophthalmol Vis Sci. 2003;44(3):1097-103.

17. Eibl KH, Banas B, Kook D, et al. Alkylphosphocholines: a new therapeutic option in glaucoma filtration surgery. Invest Ophthalmol Vis Sci. 2004;45(8):2619-24.

18. Mead AL, Wong TT, Cordeiro MF, Anderson IK, Khaw PT. Evaluation of anti-TGF-beta2 antibody as a new postoperative anti-scarring agent in glaucoma surgery. Invest Ophthalmol Vis Sci. 2003;44(8):3394-401.

19. Memarzadeh F, Varma R, Lin LT, et al. Postoperative use of bevacizumab as an antifibrotic agent in glaucoma filtration surgery in the rabbit. Invest Ophthalmol Vis Sci. 2009;50(7):3233-7.

20. Honjo M, Tanihara H, Kameda T, Kawaji T, Yoshimura N, Araie M. Potential role of Rho-associated protein kinase inhibitor Y-27632 in glaucoma filtration surgery. Invest Ophthalmol Vis Sci. 2007;48(12):5549-57.

21. Levine SJ, Larivee P, Logun C, Angus CW, Ognibene $\mathrm{FP}$, Shelhamer JH. Tumor necrosis factor-alpha induces mucin hypersecretion and MUC-2 gene expression by human airway epithelial cells. Am J Respir Cell Mol Biol. 1995;12(2):196-204.

22. Joussen AM, Poulaki V, Mitsiades N, et al. Nonsteroidal anti-inflammatory drugs prevent early diabetic retinopathy via TNF-alpha suppression. FASEB J. 2002;16(3):438-40.

23. Sartani G, Silver PB, Rizzo LV, et al. Anti-tumor necrosis factor alpha therapy suppresses the 
induction of experimental autoimmune uveoretinitis in mice by inhibiting antigen priming. Invest Ophthalmol Vis Sci. 1996;37(11):2211-8.

24. Khan SB, Cook HT, Bhangal G, Smith J, Tam FW, Pusey CD. Antibody blockade of TNF-alpha reduces inflammation and scarring in experimental crescentic glomerulonephritis. Kidney Int. 2005;67(5): 1812-20.

25. Karkar AM, Smith J, Pusey CD. Prevention and treatment of experimental crescentic glomerulonephritis by blocking tumour necrosis factor-alpha. Nephrol Dial Transpl. 2001;16(3):518-24.

26. Di Sabatino A, Ciccocioppo R, Benazzato L, Sturniolo GC, Corazza GR. Infliximab downregulates basic fibroblast growth factor and vascular endothelial growth factor in Crohn's disease patients. Aliment Pharmacol Ther. 2004;19(9):1019-24.

27. Maini R, St Clair EW, Breedveld F, et al. Infliximab (chimeric anti-tumour necrosis factor alpha monoclonal antibody) versus placebo in rheumatoid arthritis patients receiving concomitant methotrexate: a randomised phase III trial. ATTRACT Study Group. Lancet. 1999;354(9194):1932-9.

28. Lewis JD. Anti-TNF antibodies for Crohn's disease-in pursuit of the perfect clinical trial. N Engl J Med. 2007;357(3):296-8.

29. Sfikakis PP, Markomichelakis N, Alpsoy E, et al. Anti-TNF therapy in the management of Behcet's disease-review and basis for recommendations. Rheumatology. 2007;46(5):736-41.

30. Clegg DO. Treatment of ankylosing spondylitis. J Rheumatol Suppl. 2006;78:24-31.

31. Theodossiadis PG, Markomichelakis NN, Sfikakis PP. Tumor necrosis factor antagonists. Retina. 2007;27(4):399-413.

32. Hale S, Lightman S. Anti-TNF therapies in the management of acute and chronic uveitis. Cytokine. 2006;33(4):231-7.

33. Lindstedt EW, Baarsma GS, Kuijpers RW, van Hagen PM. Anti-TNF-alpha therapy for sight threatening uveitis. Br J Ophthalmol. 2005;89(5):533-6.

34. Odorcic S, Keystone EC, Ma JJ. Infliximab for the treatment of refractory progressive sterile peripheral ulcerative keratitis associated with late corneal perforation: 3-year follow-up. Cornea. 2009;28(1):89-92.

35. Nishida T, Shibuya E, Asukata Y, et al. Clinical course before and after cataract and glaucoma surgery under systemic infliximab therapy in patients with Behcet's disease. Case Rep Ophthalmol. 2011;2(2):189-92.
36. Koike A, Handa T, Zako M. Trabeculotomy in a Behcet's disease patient one week after infliximab administration. Case Rep Ophthalmol. 2012;3(1): $151-5$.

37. Khaw PT, Chang L, Wong TT, Mead A, Daniels JT, Cordeiro MF. Modulation of wound healing after glaucoma surgery. Curr Opin Ophthalmol. 2001; 12(2):143-8.

38. Chu WM. Tumor necrosis factor. Cancer Lett. 2013;328(2):222-5.

39. Ito A, Sato T, Iga T, Mori Y. Tumor necrosis factor bifunctionally regulates matrix metalloproteinases and tissue inhibitor of metalloproteinases (TIMP) production by human fibroblasts. FEBS Lett. 1990;269(1):93-5.

40. Hsu H, Shu HB, Pan MG, Goeddel DV. TRADD-TRAF2 and TRADD-FADD interactions define two distinct TNF receptor 1 signal transduction pathways. Cell. 1996;84(2):299-308.

41. Fajardo LF, Kwan HH, Kowalski J, Prionas SD, Allison AC. Dual role of tumor necrosis factor-alpha in angiogenesis. Am J Pathol. 1992;140(3):539-44.

42. Regatieri CV, Dreyfuss JL, Melo GB, Lavinsky D, Farah ME, Nader HB. Dual role of intravitreous infliximab in experimental choroidal neovascularization: effect on the expression of sulfated glycosaminoglycans. Invest Ophthalmol Vis Sci. 2009;50(11):5487-94.

43. Rapala K, Laato M, Niinikoski J, et al. Tumor necrosis factor alpha inhibits wound healing in the rat. Euro Surg Res. 1991;23(5-6):261-8.

44. Salomon GD, Kasid A, Cromack DT, et al. The local effects of cachectin/tumor necrosis factor on wound healing. Ann Surg. 1991;214(2):175-80.

45. Mooney DP, O'Reilly M, Gamelli RL. Tumor necrosis factor and wound healing. Ann Surg. 1990;211(2):124-9.

46. Austgulen R, Espevik T, Nissen-Meyer J. Fibroblast growth-stimulatory activity released from human monocytes. The contribution of tumour necrosis factor. Scand J Immunol. 1987;26(6):621-9.

47. Duncan MR, Berman B. Differential regulation of collagen, glycosaminoglycan, fibronectin, and collagenase activity production in cultured human adult dermal fibroblasts by interleukin 1-alpha and beta and tumor necrosis factor-alpha and beta. J Invest Dermatol. 1989;92(5):699-706.

48. Kovacs EJ. Fibrogenic cytokines: the role of immune mediators in the development of scar tissue. Immunol Today. 1991;12(1):17-23. 